\section{Who's Watching the Kids?}

As many readers may know, I am an oncologist who treats adults. Because I'm an academic subspecialist, I treat adults with pancreatic cancer, often a miserable unforgiving disease. But, no matter how sick the patient is or how many clinical issues are competing for my attention, I always start my first meeting with a new patient by understanding them as an individual — what their profession is, what their daily life is like, who supports them emotionally, what they do for fun. Only when I understand them am I truly able to care for their needs.

Because I treat a disease that generally afflicts older adults, most of the time my patients' children are grown and have already reached many of the milestones that mark a productive life. But occasionally, I see younger patients who still have young children at home. My heart breaks for them. For I know that this cancer is affecting not only the patient and their spouse or partner but also very young, vulnerable people who may not yet have the capacity to understand what is happening.

I've read enough about this to know that kids experiencing emotional trauma can begin to think about their situation in ways we might never expect. For instance, they could wonder if perhaps the fact that they misbehaved somehow caused their parent to become ill. Or they might misinterpret excessive attention to someone else in the family as evidence that they aren't loved anymore. Many children don't seem to want to talk about the problem or may even seem to ignore it. Many parents take this as a clue that they should keep the details among the grown-ups and avoid discussing anything with the kids. They don't know that the kids may be imaging outcomes that are even worse than what is actually unfolding.

My point here is simple: we need to understand how to better support families who are experiencing cancer and help bring the children of affected parents more effectively into the process. No one ever taught me as a provider how to counsel an affected parent; I basically figured it out on my own, but I admit I did this through trial and error. Our oncology curriculum should give us the skills to recognize when issues are present and, knowing that not everyone needs a referral to a professional therapist, provide some education for parents and some concrete suggestions about informing and involving the children. I honestly don't think this type of educational reform would be hard to do.

We spend a lot of time agonizing over threats to the Affordable Care Act, the rising costs of care, the inconveniences of MACRA and HIPAA-I could go on. But we don't spend much time at all talking about some of the more basic things our patients struggle with. Taking care of the emotional needs of kids whose parents are battling cancer seems like a goal we can all support.

What do you think? Please e-mail correspondence (include contact information) to JNCCN@nccn.org or log into www.editiorialmanager.com/JNCCN to submit a Letter to the Editor.

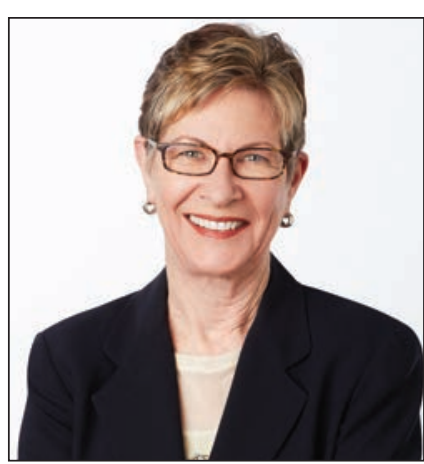

Margaret Tempero, MD

Margaret Tempero, MD, is a Professor of Medicine and Director of the UCSF Pancreas Center and editor-in-chief of JNCCN. Her research career has focused on pancreatic ductal adenocarcinoma, especially in the area of investigational therapeutics. Dr. Tempero has served on the ASCO Board of Directors and as ASCO President. She currently serves on the ASCO Conquer Cancer Foundation Board. She codirected the AACR/ASCO Methods in Clinical Cancer Research and taught this course and similar courses in Europe and Australia. She was founding Chair of the $\mathrm{NCl}$ Clinical Oncology Study Section and served as a member and Chair of the NCl Board of Scientific Counselors Subcommittee $A$. She is a member of the Scientific Steering Committee and Chair of the Clinical and Translational Study Section for the Cancer Prevention \& Research Institute of Texas. She is or has been on the Scientific Advisory Boards of the Lustgarten Foundation, the Pancreatic Cancer Action Network, the $V$ Foundation, The Alberta Canada Cancer Board, and the EORTC. She served as a member of the Oncology Drug Advisory Committee for the FDA. She has served as Deputy Director and Interim Director for the UNMC Eppley Cancer Center. She is Chief Emeritus of the Division of Medical Oncology at UCSF and served as the founding Deputy Director and Director of Research Programs at the UCSF Helen Diller Family Comprehensive Cancer Center.

doi: $10.6004 / j n c c n .2017 .0170$

The ideas and viewpoints expressed in this editorial are those of the author and do not necessarily represent any policy, position, or program of NCCN. 